\title{
POWER PLANT IN ABSTRACTION MODEL USAGE FOR MANAGEMENT
}

\section{Janusz Krzysztof Grabara}

\author{
Faculty of Mangement, Czestochowa University of Technology, Armii Krajowej 19B, 42-200 Czestochowa, Poland \\ grabara@zim.pcz.czest.pl
}

\begin{abstract}
Power plant structure can be introduced in different ways. One of such ways is the tables used is structural analysis, which take into consideration organisational and technological divisions or determine directions of technical development in enterprise with use of simulation methods. All methods that optimise management decisions can be introduced as right structural models.

It is necessary to think whether for Management System there is possibility to create universal structure, which allows building management structure model. The model has to fulfill certain requirement at the same time as simple as possible to implement to management computer system as a module of integrated system.

The paper it is a trial of theoretical introducing of such model, which take into consideration streams of management system elements and decisions and their interactions. This model consists of matrix mutual connections of the system elements and decisions.
\end{abstract}

Keywords: Management system, matrix, set.

\section{INTRODUCTION}

Management system present itself as formal arrangement composed from ordered two elements of systems $\mathrm{A}$ and set $\mathrm{R}$ of their characteristics or relation between them.

$$
\mathrm{S}-(\mathrm{A}, \mathrm{R})
$$

where:

$$
\begin{aligned}
& \mathrm{A}=\left\{\mathrm{a}_{1}, \mathrm{a}_{2}, \ldots, \mathrm{a}_{\mathrm{n}}\right\} \\
& \mathrm{R}=\left\{\mathrm{r}_{1}, \mathrm{r}_{2}, \ldots, \mathrm{r}_{\mathrm{n}}\right\}
\end{aligned}
$$

If $R^{p}$ means $p$ - reasoned relation set between elements of set $A$, that ensure inclusion

$$
R^{p} \subset A^{p} \cap R
$$

where: $\mathrm{A}^{\mathrm{p}}=\mathrm{A} \times \mathrm{A} \times \ldots \times \mathrm{A}$ means $p$ times Cartesian product of set $A$ by itself, so $p$ - is Cartesian power.

The most interesting in power plant management system $S$ are $R^{l}$ and $R^{2}$ sets 1 - reasoned relation (the characteristics of elements) and 2- reasoned relation, that is links of A set elements in two elements, so the characteristics of two elements.

\section{POWER PLANT SYSTEM}

For instance: in power plant supply department, where $a_{1}, a_{2}, \ldots, a_{n}$ are elements of supply system (or "more precisely" subsystem) are parameters of supply $-R^{2}$ set can mean set of prices or other parameters of supplied materials (fuel - coal, gas, and other materials). Owing to fact that the management system $S$ is functioning in the space $\Omega$, and which it is a proper part of this space: $S \subset \Omega, \quad$ is indispensable accomplishment of generalisation of this problem.

In introduced record

$$
\mathrm{S}=\left(\mathrm{A}, \mathrm{R}, \mathrm{R}^{*}\right)
$$

sets $A, R$ and $R^{*}$ elements of the management system of internal and external relation might be shown as sum (or sequence) of multitude elements relation. In this way it obtains deeply and more detailed entrance to structure of management system S.

\section{Therefore, it could be}

$$
\mathrm{S}=\left(\mathrm{A}, \mathrm{R}, \mathrm{R}^{*}\right)
$$

where:

$$
\left\{\begin{array}{l}
A=A_{1} \cup A_{2} \cup \ldots \cup A_{S}, \\
R=R_{1} \cup R_{2} \cup \ldots \cup R_{q}, \\
R=R_{1}^{*} \cup R_{2}{ }^{*} \cup \ldots \cup R_{k}{ }^{*}
\end{array}\right.
$$


or

$$
\left\{\begin{array}{l}
A=A_{1}, A_{2}, \ldots, A_{S}, \\
R=R_{1}, R_{2}, \ldots, R_{q}, \\
R^{*}=R_{1}^{*}, R_{2}^{*}, \ldots, R_{k}^{*}
\end{array}\right.
$$

Power plant management system (S) of enterprise creates set of elements, internal relation between elements of this system and external relation among elements of $\mathrm{S}$ system and elements of surrounding S'.

Basic generalised convergence:

$$
\mathrm{S}=\left(\mathrm{A}, \mathrm{R}, \mathrm{R}^{*}\right)
$$

is a base to initiate more detailed elements of the management systems, which then is a sequence:

$$
\mathrm{S}=(\mathrm{M}, \mathrm{B}, \mathrm{L}, \mathrm{Z}, \mathrm{W}, \mathrm{R})
$$

where:

$\mathrm{R}$ - set of relations,

M- inventories,

B- material base,

L- workers,

Z- power plant actions

W- realisation of actions determining the existence and function purpose.

Owing to practical reasons as elements of management system assume:

- integrated computer networks which make possible inflow of information streams; computer system is only a tool in executing the purpose,

- technical resources, which move and store material stream,

- managerial personnel, which through managing of all power plant actions create various decisional variants in the field of managements system.

To carry out characteristics of power plant system, in methodical procedures is required adoption of the basic component of system, to which belong:

1. purpose, directed on activity of all subsystems

2. exits, as a derivative (function) of purpose in the form of results of system's activity (products or services),

3. entrances, which decided on power system (materials, information, staff),

4. transformation process of entrance on exit determined as a sequence of basic process actions,
5. surrounding, created by suppliers, receivers, distributors, banks etc.,

6. equipment, to which belongs buildings, transport resources, machines,

7. human resources i.e. number and structure, qualification and abilities.

Presented parameters and attributes of power plant management system show that for basic condition of functioning assumes junction of the component parts. The diversification concerns the extent of junction, which can be measure by scalar or vector. Scalar measurements are characteristics for physical and chemical systems as well as in a certain measure for social systems. For binding energy judge the junction measurement. Economic systems and also management systems are subjected to other measurement of character. Vector, or vector - quantitative dimension is a typical measurement of junction management system. Numerous theories of measurement are a sufficient base to state that actually there is no universal measurement of link power. Its essence determines components' nature and junction links. To assume many of guidelines range of link power fulfils closed range $[0,1]$.

Undertaking above relations assume that for $\mathrm{m} \geq$ $2 \mathrm{~s}_{1}, \mathrm{~s}_{2}, \mathrm{~s}_{3}, \ldots, \mathrm{s}_{\mathrm{m}}$ elements which create management system $S$, i.e. $S=\left\{s_{1}, s_{2}, s_{3}, \ldots, s_{m}\right\}$, are represented in three - dimensional space $\mathrm{R}^{3}$ by suitably not zero vectors: $\vec{w}_{1}, \vec{w}_{2}, \vec{w}_{3}, \ldots, \vec{w}_{m}$. We implement measurement of connection $\mu_{i j} \quad s_{i}$ and $s_{j}$ elements of system $\mathrm{S}$ as

$$
\mu_{i, j}=\frac{\vec{w}_{i} \cdot \vec{w}_{j}+\left|\vec{w}_{i}\right| \cdot\left|\vec{w}_{j}\right|}{2\left|\vec{w}_{1}\right| \cdot\left|\vec{w}_{2}\right|}
$$

From definition of measurement $\mu_{\mathrm{ij}}$ ensues that

$$
\begin{gathered}
0 \leq \mu_{\mathrm{ij}} \leq 1, \\
\text { because }\left|\vec{w}_{i} \vec{w}_{i}\right| \leq\left|\vec{w}_{i}\right| \cdot\left|\vec{w}_{j}\right|
\end{gathered}
$$

to carry out $\quad \mathrm{u}_{i, j} \quad$ for $\mathrm{i}, \mathrm{j}=1,2 \ldots, \mathrm{m}(\mathrm{i} \neq \mathrm{j})$ among elements $\mathbf{S}_{i}$ and $\mathbf{S} j$ of the managementsystem $\mathbf{S}$ we can determine numerous measurement $u$ (S) connection of system S or measurement of link power of system $\mathrm{S}$ as arithmetical average:

$$
u(S)=\frac{\sum_{\substack{i, j=1 \\ i \neq j}}^{m} u_{i . j}}{\left(\frac{m}{2}\right)}
$$


that is

$$
\mathrm{u}(\mathrm{S})=\frac{2\left(u_{11}+u_{1 m}+u_{23}+\ldots+u_{2 m}+\ldots+u_{m-1, m}\right.}{m(m-1)}
$$

From the characteristics of arithmetical average follows that

$$
\mathbf{0} \leq \mathbf{u}(\mathbf{S}) \leq \mathbf{1}
$$

\section{cause $\mathbf{u} i, j \in<\mathbf{0 , 1}>$ for each two elements (i,j)}

If $u(S)=0$ it means that system $S$ will find in disintegration, however when $u(S)=1$, it assumes that system $S$ is maximum bounded or has maximum connection.

Based on analogy we indicate on relationship in the range of assumed values through the elements of management system.

Elements $\mathbf{S} i, \mathbf{s}_{j}$ are consistent, when $\mathrm{u}_{i, j}=1$ or $\mathrm{u} i, j$ is closely to number 1 .

Elements $\mathrm{S}_{i}, \mathrm{~S}_{j}$ are inconsistent (or conflicted), when $\mathrm{u}_{i, j}=0$ or $\mathrm{u}_{i, j}$ is closely to number 0 .

Designing management system $\mathrm{S}$ has to avoid couple of $\left(\mathbf{S}_{i}, \mathbf{S}_{j}\right)$ two inconsistent elements through elimination $\mathbf{s} i$ element or $\mathrm{s}_{j}$ element. Process of choosing $\mathrm{S} i$ or $\mathrm{s} j$ elements to elimination might be consist in calculation two numbers:

$$
\begin{gathered}
a=\sum_{\substack{k=1 \\
k \neq i}}^{m} u_{i k} \\
b=\sum_{\substack{k=1 \\
k \neq j}}^{m} u_{k, j}
\end{gathered}
$$

If $\mathrm{a}=\mathrm{b}, \mathrm{s} i$ element or $\mathrm{s} j$ element is eliminated from system.

When $\mathrm{a}<\mathrm{b}$, "more conflicted element" it means $\mathrm{S} i$ element is eliminated.

In case when $\mathrm{a}>\mathrm{b}, \mathrm{s} j$ element is eliminated.

To order the process of elimination some (more conflicted) elements, certain measurable criteria should be given and have to be fulfilled e.g.

$$
\begin{array}{ll}
u_{i, j} \geq p, & \text { where } 0<\mathrm{q}<1 \\
u(S) \leq q, & \text { and } \\
u \text { where } 0<\mathrm{q}<1
\end{array}
$$

To hard criteria may lead in certain cases to elimination m-1 elements from among $s_{1}, s_{2}, \ldots$

,$s_{m}$, that is almost annihilation of system $\mathrm{S}$.

It means that numbers $p, q \in(0,1)$, should be a subject of detailed analyses of the management system in aspects of measurable categories. Therefore initial thesis is confirmed and according to it, designs of the management system relay on vector or vector-quantitative dimension.

In present management systems special part falls to computer science technicians. For basic conditions of using information and computing in management might be recognised (Hanus \& Kasperek 1997)

- information as a subject of energy production processes,

- inflow of development of computer science to model of management system,

- interaction of computer systems to management systems.

To judge the information as an object of flow thereby it is placed in management system. Processes of information flow in time and space are identified with processes of physical goods flow. Engaged equipment, which makes possible accumulating, processing and sending information is more efficient but costs of buying its are high. Moreover not large experience of enterprises, which sending necesarry information cause that nowadays it's very hard to call aforementioned information as a "splendid good" flowing in the management system. The works are conducted systematically and lead to improve the computing techniques using in management systems. Working out computer programmes in which basic parameters that describe management system are taken into consideration and conduct to improvement of venture in this domain.

Necessary data accumulating on enterprise's needs may come from inside or outside. External data come from managerial researches and monitoring of surrounding (continuous researches). Above-mentioned researches may include accumulation from the original or derivative sources. Taking advantage from original sources rely on first time data collecting required by given research. In external sources of managerial information can be made the division on domestic and foreign sources.

The using of original internal sources can concern in particular (Hanus \& Kasperek 1997):

- measurement of product quality and additional services;

- estimation of functioning of distribution system as well as its reliability and flexibility in delivery's realisation;

- spatial placing of distribution partners, final 
customers;

- to carry out interviews with workers in order to improve functioning of system monitoring company's inside;

- general estimation of company's activity.

Connection of effects from carrying out data analysis and obtained information from external and internal sources gives full image of enterprise's situation.

Model of management system was shown in the form of block diagram, but nowadays sciences of management admit this form of projection as insufficient. In order to effective running of analysis, the contemporary tools which assist analysis processes, which using computing technologies have to be taken into consideration. That is way formalisation of records has to very high. Those requirements fulfil method of Matrix Structures Show (EMPEES) of economic systems worked out by W.J. Wesołowski (Wesołowski 1996). Directed matrix record clearly demonstrates the couplings, which have character of feedback. Their records lay symmetrically spread on oppose sides of zero diagonal line.

Matrix, closely formalised projection of structure of management showed in table 1, makes possible full exploitation of computer aid in the process of management.

Using the matrix projection of elements' configuration and streams, the relation $\phi_{i k}$, created by particular elements $D_{i}$ and steering flow of interactions of streams $s_{k l}$ as function of relations may be presented. Above - mentioned relations are follow:

- relations $z_{k i}$ flowing from subjected elements,

- relations $d_{i j}$ flowing from procedural elements.

Using here and aforementioned characteristics of matrix record allows read for each element all links ingoing to its and outgoing from its. And so:

Table 1. Matrix projection of elements configuration as well as procedural and subjected streams of management system of work security in power plants

\begin{tabular}{|c|c|c|c|c|c|c|c|c|c|c|c|}
\hline & $\mathbf{W}_{1}$ & $\mathbf{W}_{2}$ & $\mathbf{W}_{3}$ & $\mathbf{W}_{4}$ & $\mathbf{W}_{5}$ & $\mathrm{~W}_{6}$ & $\mathbf{D}_{1}$ & $\mathbf{D}_{2}$ & $\mathbf{D}_{\mathbf{3}}$ & $\mathbf{D}_{4}$ & $\mathrm{D}_{5}$ \\
\hline $\mathbf{D}_{1}$ & $\phi_{11}$ & $\phi_{12}$ & $\phi_{13}$ & $\phi 14$ & $\phi_{15}$ & $\phi_{16}$ & 0 & $d_{12}$ & $\mathbf{d}_{13}$ & $\mathbf{D}_{14}$ & $\mathbf{d}_{15}$ \\
\hline $\mathbf{D}_{2}$ & $\phi 21$ & $\phi_{22}$ & $\phi_{23}$ & $\phi_{24}$ & $\phi_{25}$ & $\phi 26$ & $\mathbf{d}_{21}$ & $\mathbf{0}$ & $\mathbf{d}_{23}$ & $\mathbf{D}_{24}$ & $d_{25}$ \\
\hline $\mathbf{D}_{3}$ & $\phi 31$ & $\phi 32$ & $\phi 33$ & $\phi_{34}$ & $\phi_{35}$ & $\phi 36$ & $\mathbf{d}_{31}$ & $\mathbf{d}_{32}$ & 0 & $\mathbf{D}_{34}$ & $\mathbf{d}_{35}$ \\
\hline $\mathbf{D}_{4}$ & $\phi 41$ & $\phi 42$ & $\phi 43$ & $\phi 44$ & $\phi 45$ & $\phi 46$ & $\mathrm{~d}_{41}$ & $\mathrm{~d}_{42}$ & $d_{43}$ & 0 & $\mathrm{d}_{45}$ \\
\hline D5 $_{5}$ & $\phi 51$ & $\phi 52$ & $\phi 53$ & $\phi 54$ & $\phi 55$ & $\phi 56$ & $d_{51}$ & $d_{52}$ & $d_{53}$ & D54 $_{54}$ & 0 \\
\hline $\mathbf{W}_{\mathbf{1}}$ & $\mathbf{s}_{11}$ & $\mathrm{~s}_{12}$ & $\mathbf{s}_{13}$ & $\mathrm{~s}_{14}$ & $\mathrm{~s}_{15}$ & $s_{16}$ & $z_{11}$ & $\mathrm{z}_{12}$ & $z_{13}$ & $\mathrm{Z}_{14}$ & $\mathrm{z}_{15}$ \\
\hline $\mathbf{W}_{2}$ & $\mathbf{s}_{21}$ & $\mathbf{s}_{22}$ & $\mathbf{s}_{23}$ & $\mathbf{s}_{24}$ & $\mathbf{s}_{25}$ & $s_{26}$ & $z_{21}$ & $z_{22}$ & $\mathbf{z}_{23}$ & $\mathrm{Z}_{24}$ & $z_{25}$ \\
\hline $\mathbf{W}_{\mathbf{3}}$ & s31 & s32 & s33 & s34 & s35 & s36 & $\mathrm{z}_{31}$ & $\mathrm{z}_{32}$ & $\mathbf{z}_{33}$ & $\mathrm{Z}_{34}$ & $z_{35}$ \\
\hline $\mathbf{W}_{4}$ & $s_{41}$ & $\mathbf{s}_{42}$ & $\mathbf{s}_{43}$ & $\mathrm{~s}_{44}$ & $\mathbf{s}_{45}$ & $s_{46}$ & $\mathbf{z}_{41}$ & $\mathbf{z}_{42}$ & $\mathbf{z}_{43}$ & $\mathrm{Z}_{44}$ & $\mathbf{z}_{45}$ \\
\hline$W_{5}$ & s51 & s52 & s53 & s54 & s55 & s56 & z51 & $\mathrm{z}_{52}$ & $z_{53}$ & $\mathrm{Z}_{54}$ & z55 \\
\hline $\mathrm{W}_{6}$ & $\mathbf{s}_{61}$ & $\mathbf{s}_{62}$ & $\mathbf{s}_{63}$ & $\mathbf{s}_{64}$ & $\mathbf{s}_{65}$ & s66 & $\mathrm{z}_{61}$ & $\mathrm{z}_{62}$ & $\mathrm{z}_{63}$ & $\mathrm{Z}_{64}$ & $\mathbf{z}_{65}$ \\
\hline
\end{tabular}


Relation ensuring from inventories $\mathrm{M}\left(\mathrm{D}_{1}\right)$

$\phi_{11}=\mathrm{f}_{1}\left(\mathrm{~d}_{12}, \mathrm{~d}_{13}, \mathrm{~d}_{14}, \mathrm{~d}_{15}, \mathrm{~d}_{21}, \mathrm{~d}_{31}, \mathrm{~d}_{41}, \mathrm{~d}_{51}, \mathrm{z}_{11}, \mathrm{z}_{21}\right.$, $\left.\mathrm{z}_{31}, \mathrm{z}_{41}, \mathrm{z}_{51}, \mathrm{z}_{61}\right)$

relation ensuring from material base $\mathrm{B}\left(\mathrm{D}_{2}\right)$

$\phi_{22}=\mathrm{f}_{2}\left(\mathrm{~d}_{21}, \mathrm{~d}_{23}, \mathrm{~d}_{24}, \mathrm{~d}_{25}, \mathrm{~d}_{12}, \mathrm{~d}_{32}, \mathrm{~d}_{42}, \mathrm{~d}_{52}, \mathrm{z}_{12}, \mathrm{z}_{22}\right.$, $\left.\mathrm{z}_{32}, \mathrm{z}_{42} \mathrm{z}_{52}, \mathrm{z}_{62}\right)$

relation ensuring from properly work of people who realise power plant actions $\mathrm{L}\left(\mathrm{D}_{3}\right)$

$$
\phi_{33}=\mathrm{f}_{3}\left(\mathrm{~d}_{31}, \mathrm{~d}_{32}, \mathrm{~d}_{34}, \mathrm{~d}_{35}, \mathrm{~d}_{13}, \mathrm{~d}_{23}, \mathrm{~d}_{43}, \mathrm{~d}_{53}, \mathrm{z}_{13}, \mathrm{z}_{23}\right. \text {, }
$$$$
\left.\mathrm{z}_{33}, \mathrm{z}_{43}, \mathrm{z}_{53}, \mathrm{z}_{63}\right)
$$

relation ensuring from power plant actions $\mathrm{Z}$

$$
\begin{aligned}
& \phi_{44}=\mathrm{f}_{4}\left(\mathrm{~d}_{41}, \mathrm{~d}_{42}, \mathrm{~d}_{43}, \mathrm{~d}_{45}, \mathrm{~d}_{14}, \mathrm{~d}_{24}, \mathrm{~d}_{34}, \mathrm{~d}_{54}, \mathrm{z}_{14}, \mathrm{z}_{24},\right. \\
& \left.\mathrm{z}_{34}, \mathrm{z}_{44}, \mathrm{z}_{54}, \mathrm{z}_{64}\right)
\end{aligned}
$$

relation ensuring from realisation of exercise determining the existence and function purpose $\mathrm{W}$ $\left(\mathrm{D}_{5}\right)$

$$
\begin{aligned}
& \phi_{55}=\mathrm{f}_{5}\left(\mathrm{~d}_{51}, \mathrm{~d}_{52}, \mathrm{~d}_{53} \mathrm{~d}_{54}, \mathrm{~d}_{15}, \mathrm{~d}_{25}, \mathrm{~d}_{35}, \mathrm{~d}_{45}, \mathrm{z}_{15}, \mathrm{z}_{25},\right. \\
& \left.\mathrm{z}_{35}, \mathrm{z}_{45} \mathrm{z}_{55}, \mathrm{z}_{65}\right)
\end{aligned}
$$

Such record of model of management system is favourable for its implementation to structure of integrated management computer system, because in unequivocal way allows to determine relation and give adequate weights to particular elements in pursuance of their range of interaction.

Matrix record of investigated structure will provide identification of those relation as a function of factors ingiong to framework of system. It will be relations effecting on particular elements of management system and flowing from blocks detailed determining relation occurred in system. Those relations can be assented to binary record and then present them in graphical way. In this purpose it is possible to apply two - valued Boole's algebra (presented by Shannon in 1938). This algebra is known as algebra of switching system. Boole's algebra is used in practical way to describe systems built from two - state relays. Those relays are able to achieve two states: state of conducting - described as 1 and non - conducting state described as 0 . Using this algebra is a consequence of analogy and because of it is, can be made certain interpretation of the management system. When all elements and relations of management system are taken into consideration, the function described them (formal record) will equal a value 1 and it means initiating of efficient management system. However if one of elements, which create the management system won't be taken into consideration, the value of function is equal 0 and it means lack of efficient management system.

\section{REFERENCES}

[1] Hanus P., Kasperek M. (1997), Computer system in management, Habex, Gliwice

[2] Wesołowski W. J. (1996) Metodyka badań w dziedzinie nauk o zarzadzaniu. Prywatna Wyższa Szkoła Handlowa, Drukarnia Wydawnictw Naukowych, Warszawa

Dr. Janusz Grabara has been an academic lecturer with 28year professional experience. In 1997 he started work as a lecturer and then as a senior lecturer for Faculty of Management in Czestochowa University of Technology. Working as a lecturer and senior lecturer he has taught at

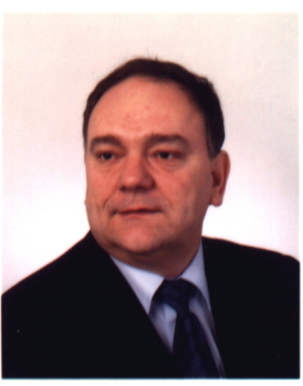
Master's and Bachelor's studies on management and production engineering as well as IT sciences and econometrics and a range of didactic courses on the following subjects:

- Management IT systems design,

- Computer Aided Production Management,

- Computer Simulation,

- IT systems for Logistics,

- Management in Health \& Safety and

Environmental Protection.

The research team headed by Prof. Maria NowickaSkowron and, since 2002 by Janusz Grabara, has become a renowned expert in solving complex scientific issues in the area of logistics and computerization of management processes, especially for energy industry sector. The team is currently cooperating with various power plants all over the country. Total number of orders and expert's reports amounts to over 40 studies which constitute a basis for setting the directions of development in cooperating energy sector companies. Interests: deep knowledge of rules of management, positively verified by effective organization of a range of scientific conferences on IT systems, logistics management, particularly on energy industry sector, member of Scientific Council of Institute of Control Systems in Chorzów. 